ఠ

\title{
miR- 17 as a diagnostic biomarker regulates cell proliferation in breast cancer
}

This article was published in the following Dove Press journal:

OncoTargets and Therapy

27 January 2017

Number of times this article has been viewed

\author{
Fangliang Yang ${ }^{1,2}$ \\ Yuan $\mathrm{Li}^{\prime}$ \\ Lingyun $\mathrm{Xu}^{\prime}$ \\ Yulan Zhu' \\ Haiyan Gao' \\ Lin Zhen' \\ Lin Fang ${ }^{2}$
}

'Department of Thyroid and Breast Surgery, Changzhou No 2 People's Hospital Affiliated to Nanjing Medical University, Changzhou, ${ }^{2}$ Department of Thyroid and Breast Surgery, Shanghai No 10 People's Hospital, Clinical College of Nanjing Medical University, Shanghai, People's Republic of China
Correspondence: Lin Fang Department of Thyroid and Breast Surgery, Shanghai No 10 People's Hospital, Clinical College of Nanjing Medical University, No 30I Yanchang Road, Shanghai 200072, People's Republic of China

Tel +8651988107307

Fax +8651988115560

Email fanglin_unv@sina.com
Background: MicroRNAs (miRNAs) have been shown to be involved in the initiation and progression of cancers in the literature. In this study, we aimed to evaluate the clinicopathological role of miR-17 in breast cancer.

Materials and methods: The expression of miR-17 was measured in 132 breast cancer tissues and paired adjacent normal tissues by using real-time quantitative polymerase chain reaction. The association between miR-17 expression levels and clinicopathological parameters was also analyzed. 3-(4,5-Dimethylthiazol-2-yl)-2,5-diphenyltetrazolium bromide and flow cytometry assays were used to investigate the role of miR-17 in the regulation of breast cancer cells.

Results: The expression of miR-17 was remarkably increased in breast cancer tissues and cell lines. Clinical association analysis revealed that a high expression of miR-17 was prominently associated with poor survival time in breast cancer. Overexpression of miR-17 promoted cell proliferation and induced tumor growth.

Conclusion: Our findings clarified that the upregulation of miR-17 played a vital role in breast cancer progression and suggested that miR-17 could be used as a prognostic biomarker for breast cancer.

Keywords: miR-17, breast cancer, biomarker, cell proliferation

\section{Introduction}

Breast cancer is one of the most common cancers worldwide, ${ }^{1}$ with differences among tumors that are driven by multiple genetic/epigenetic alterations and molecular events. ${ }^{2}$ Despite the improved prognosis of breast cancer patients due to early diagnosis, radical surgery and the development of adjuvant therapy, breast cancer remains one of the most common type of cancers among women. ${ }^{3,4}$ Prognostic factors that are frequently used for making clinical decisions in breast cancer are age, tumor size, status of lymph nodes, histological types of the tumor, pathological grade, and hormone receptor status. ${ }^{5,6}$ However, more biomarkers are needed for therapy and prediction of outcomes because human breast cancers are diverse in their genetic nature and their response to therapy.

MicroRNAs (miRNAs) are small noncoding endogenous RNA of 20-25 nucleotides that negatively regulate expression of target genes at the posttranscriptional level through mRNA degradation and translational repression. ${ }^{7}$ Numerous studies have demonstrated that aberrantly expressed miRNAs are involved in diverse diseases, ${ }^{8-10}$ including cancer. Some miRNAs act as tumor suppressors or oncogenes and play critical roles in many aspects of breast cancer carcinogenesis, including cell proliferation, differentiation, metastasis, and angiogenesis. ${ }^{11-17}$ Given the high stability of miRNAs in formalin-fixed, paraffin-embedded (FFPE) tissue and circulation, there is growing recognition of the possibility of miRNAs as biomarkers for cancer diagnosis, prognosis, and prediction of treatment response. ${ }^{18-21}$ 
Recently, miR-17 has been shown to play a significant role in the pathogenesis of various cancers. The miR-17-5p was overexpressed in ovarian cancer cells, which activated AKT by downregulation of phosphatase and tensin homolog (PTEN) in ovarian cancer cells. ${ }^{22}$ Overexpression of miR-17 significantly increases cell motility and migration of melanoma cells by inhibiting the translation of ETV $1 .{ }^{23}$ High levels of the oncogenic miRNA (oncomiR) guide strand called miR-17-5p is overexpressed in triple negative breast cancer (TNBC) and can inhibit ribosomal translation of tumor suppressor gene mRNAs, such as programmed cell death 4 (PDCD4) or PTEN. ${ }^{24}$ miR-17 may help detecting early recurrence of colon cancer after radical surgery and adjuvant chemotherapy with high accuracy in clinical practice. ${ }^{25}$ miR-17-92 plays an oncogenic role and provides chemoresistance to cisplatin in human prostate cancer cells. ${ }^{26}$ However, little is known about the association between the level of miR-17 expression and the tumorigenesis and development.

In our study, we examined miR-17 expression in breast cancer tissues and cell lines. We also assessed the association between miR-17 expression and clinicopathological characteristics and overall survival of breast cancer patients. Moreover, we investigated the role of miR-17 in the regulation of breast cancer cells.

\section{Materials and methods}

\section{Tissue specimens}

A total of 132 breast cancer tissue specimens were obtained from patients who had undergone breast cancer surgery at the Affiliated Hospital of Nanjing Medical University, Changzhou No 2 People's Hospital, Changzhou, People's Republic of China. All the samples were shown to be correctly labeled clinically and pathologically and immediately frozen at $-80^{\circ} \mathrm{C}$ until use. The ethical committees of Changzhou No 2 People's Hospital affiliated to Nanjing Medical University approved this study, and written informed consent was obtained from all patients.

\section{Cell lines and cell culture}

Human breast cancer cell lines (MCF-7, MDA-MB-231, and MDA-MB-435S) were obtained from the Central Lab of the Affiliated Hospital of Nanjing Medical University, Changzhou No 2 People's Hospital, Changzhou, People's Republic of China. The cell lines were cultured in Roswell Park Memorial Institute 1640 medium and Dulbecco's Modified Eagle's Medium (DMEM; Thermo Fisher Scientific, Waltham, MA, USA) containing $10 \%$ fetal bovine serum (FBS; Invitrogen) and were grown in a humidified $5 \% \mathrm{CO}_{2}$ incubator at $37^{\circ} \mathrm{C}$.

\section{RNA extraction and expression analysis}

Total RNA was extracted using TRIzol reagent (Invitrogen) and a mirVana miRNA Isolation Kit (Ambion, Austin, TX, USA) according to the manufacturer's instructions. cDNA was synthesized with the RevertAid ${ }^{\mathrm{TM}}$ First Strand cDNA Synthesis Kit (Thermo Fisher Scientific). Real-time polymerase chain reaction (PCR) was performed using SYBR Green PCR Master Mix (Vazyme, Nanjing, People's Republic of China) on ABI VII7 Real-time RT-PCR system (Bio-Rad Laboratories Inc., Hercules, CA, USA). For miR-17 detection, U6 snRNA was used as an internal control. The relative levels of miRNA expression were calculated from the relevant signals by normalization with the signal of U6 snRNA expression. RNA expression levels were obtained using the comparative cycle threshold $2^{-\Delta \Delta C_{\mathrm{t}}}$ method and analyzed as mean $\pm \mathrm{SD}$.

\section{RNA oligoribonucleotides and cell transfection}

BothmiR-17 and all RNA oligoribonucleotides for in vitro studies were purchased from GenePharma (Shanghai, People's Republic of China). Their sequences were listed as follows: miR-17 scramble F1-5'-GUCCUGAGAAGGCUAGCAUAGAU-3', F2-5'-CUAUGCUAGCCUUCUCAGGACUU-3'; miR-17 mimics F1-5'-CAAAGUGCUUACAGUGCAGGUAG-3', F2-5'-ACCUGCACUGUAAGCACUUUGUU-3'; and miR-17 inhibitor F1-5'-CUACCUGCACUGUAAGCACUUUG. The transfection of RNA oligoribonucleotides was performed using Lipofectamine 2000 (Invitrogen). Unless otherwise indicated, $100 \mathrm{nM}$ of RNA duplex or $80 \mathrm{nM}$ of miRNA inhibitor was used for each transfection, and all the experiments were repeated in triplicate.

\section{Cell proliferation and cell cycle analyses}

Cell viability was analyzed using 3-(4,5-Dimethylthiazol-2yl)-2,5-diphenyltetrazolium bromide (MTT; Sigma) assays as previously described. Briefly, $5 \times 10^{3}$ cells per well were seeded into a $96-$ well plate. After miRNA transfection, the cells were maintained for 72 hours and cell viabilities were determined using a Benchmark Plus ${ }^{\mathrm{TM}}$ microplate spectrometer (Bio-Rad Laboratories Inc.). For cell cycle analysis, the cells were harvested $48 \mathrm{~h}$ following transfection, washed with PBS, and fixed in $75 \%$ ethanol at $-20^{\circ} \mathrm{C}$. After overnight fixation, the cells were washed with PBS and stained with propidium iodide (Beckman Coulter, Fullerton, CA, USA) for $30 \mathrm{~min}$. Cell cycle analysis was performed using the BD Flow Cytometry System with FACSDiva software (BD, Franklin Lakes, NJ, USA). The cell cycle distribution is presented as the percentage of cells in G1, S, and G2 phases. The data were analyzed with FlowJo v5.7.2 (BD). 


\section{Stable transfection and in vivo animal studies}

All animal experiments in this study were approved by the ethics committee of Nanjing Medical University, and the guidelines of National Animal Care and Use Committee were followed. Twenty mice were randomly divided into two groups, and each mouse was injected subcutaneously with $1 \times 10^{8}$ cells. The agomiR-17 expression constructs were generated by GenePharma, and miR-17 expression was confirmed by quantitative reverse transcription (qRT)-PCR. The tumor volume $\left(\mathrm{mm}^{3}\right)$ was measured every 7 days and was calculated using the following formula: volume $=$ width $\times$ width $\times$ height $/ 2$. The animals were sacrificed 42 days after seeding the tumor cells. All tumor grafts were excised, weighed, and harvested.

\section{Statistical analyses}

The significance of differences between groups was estimated by the Wilcoxon test for two-group comparisons and the Kruskal-Wallis test for $k$-group comparisons (with $k>2$ ). Cases were divided into two groups, high or low, using the median value of miR-17 expression as a cutoff. Fisher's exact test was used to evaluate the relationship between miR-17 expression and clinical features. Overall survival was calculated as the time from the date of surgery resection to the date of last contact or death. Survival analyses were performed using the KaplanMeier method and the log-rank test. $P$-value $<0.05$ was considered statistically significant. All statistical analyses were performed using the SPSS version 19.0 (IBM Corp, Armonk, NY, USA).

\section{Results \\ MiR-I7 is frequently upregulated in breast cancer}

In order to explore the role of miR-17 in breast carcinogenesis, we used qRT-PCR to measure miR-17 expression in breast cancer and adjacent noncancerous tissues. The expression of miR-17 was significantly increased in cancer tissues compared with adjacent normal tissues $(P<0.0001$, $\mathrm{n}=40$; Figure 1A). In addition, the expression of miR-17 was higher in tumors with pathological stages (N1 and N2, $P=0.5612 ; \mathrm{N} 1$ and N3, $P<0.05 ; \mathrm{N} 1$ and N4, $P<0.05$; Figure 1B). These data suggested that upregulated miR-17 was a frequent event in human breast cancer and could be involved in cancer progression.

We also investigated the association between the expression of miR-17 and clinicopathological characteristics. Specimens were divided into two groups according to the expression of miR-17. The data showed that the expression of miR-17 differed significantly according to human epidermal growth factor receptor 2 status $(P<0.05)$ and estrogen receptor status $(P<0.05)$. As shown in Table 1 , no difference was found between miR-17 expression and other clinical features, such as age, cyclooxygenase-2, CD44, epidermal growth factor receptor, progesterone receptor, $\mathrm{P}$-glycoprotein status, and lymph node metastasis.

\section{MiR-I7 promotes proliferation of breast cancer cells in vitro}

To determine the role of miR-17 in breast cancer cells, we detected miR-17 expression in the breast cancer cell lines MCF-7, MDA-MB-435S, and MDA-MB-231. We found
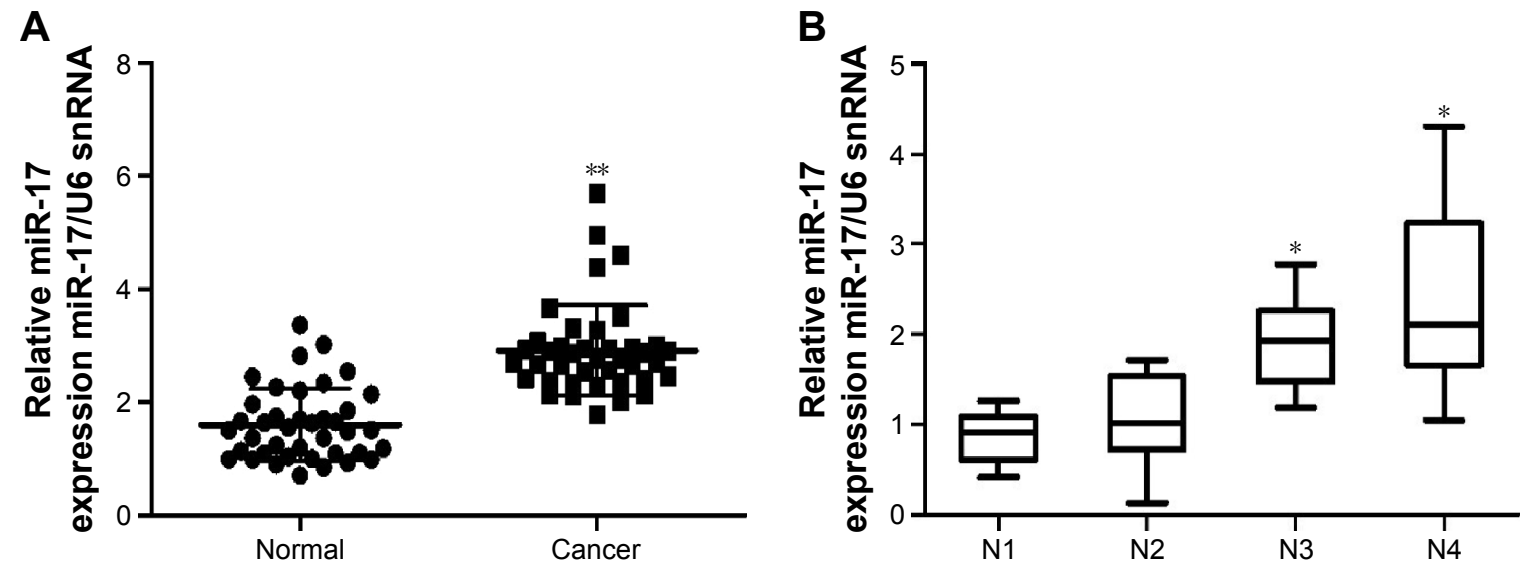

Figure I The expression of miR-I7 in breast cancer tissues.

Notes: (A) miR-17 expression was examined by qRT-PCR and normalized to U6 snRNA expression in breast cancer tissues (cancer) compared with adjacent noncancerous tissues (normal). (B) miR-I7 expression was examined by qRT-PCR in different advanced pathological stages: NI, N2, N3, and N4. $* P<0.05$ and $* * P<0.01$.

Abbreviation: $\mathrm{QRT}-\mathrm{PCR}$, quantitative reverse transcription polymerase chain reaction. 
Table I The relationship between miR- I 7 expression and clinicopathological parameters

\begin{tabular}{|c|c|c|c|}
\hline \multirow[t]{2}{*}{ Characteristics } & \multicolumn{2}{|c|}{ miR-17 expression } & \multirow[t]{2}{*}{$P$-value } \\
\hline & $\begin{array}{l}\text { Low }(n=48) \text {, } \\
n(\%)\end{array}$ & $\begin{array}{l}\text { High }(n=44) \text {, } \\
n(\%)\end{array}$ & \\
\hline Age (years) & & & 1 \\
\hline$\geq 50$ & $21(43.8)$ & $20(45.4)$ & \\
\hline$<50$ & $27(56.2)$ & $24(54.6)$ & \\
\hline cox-2 & & & I \\
\hline Positive & $23(47.9)$ & $21(47.7)$ & \\
\hline Negative & $25(52.1)$ & $23(52.3)$ & \\
\hline CD44 & & & 0.68 \\
\hline Positive & $24(50.0)$ & $24(54.5)$ & \\
\hline Negative & $24(50.0)$ & $20(45.5)$ & \\
\hline EGFR & & & 0.8 \\
\hline Positive & 15 (42.9) & $13(38.2)$ & \\
\hline Negative & $20(57.1)$ & $21(62.8)$ & \\
\hline ER & & & 0.006 \\
\hline Positive & $20(4 \mid .7)$ & $31(70.5)$ & \\
\hline Negative & $28(58.3)$ & $13(29.5)$ & \\
\hline$P R$ & & & 0.83 \\
\hline Positive & $24(50.0)$ & $21(47.7)$ & \\
\hline Negative & $24(50.0)$ & $23(52.3)$ & \\
\hline HER-2 & & & 0.0007 \\
\hline Positive & $20(4 \mid .7)$ & $34(77.3)$ & \\
\hline Negative & $28(58.3)$ & $10(22.7)$ & \\
\hline PGP & & & 0.17 \\
\hline Positive & $12(44.5)$ & $19(65.5)$ & \\
\hline Negative & $15(55.5)$ & $10(34.5)$ & \\
\hline Lymph node metastasis & & & 0.29 \\
\hline Positive & $26(54.1)$ & $29(65.9)$ & \\
\hline Negative & $22(45.9)$ & $15(34.1)$ & \\
\hline
\end{tabular}

Abbreviations: COX-2, cyclooxygenase-2; EGFR, epidermal growth factor receptor; ER, estrogen receptor; PR, progesterone receptor; HER-2, human epidermal growth factor receptor 2; PGP, P-glycoprotein.

that the expression of miR-17 was significantly higher in cancer cell lines compared with MCF10A cells (Figure 2A). Then, we transfected MCF-7 and MDA-MB-231 cells with miR-17 mimics or an inhibitor. We found that miR-17 mimics promoted miR-17 expression and miR-17 inhibitor inhibited miR-17 expression in breast cancer cells (Figure S1). MTT

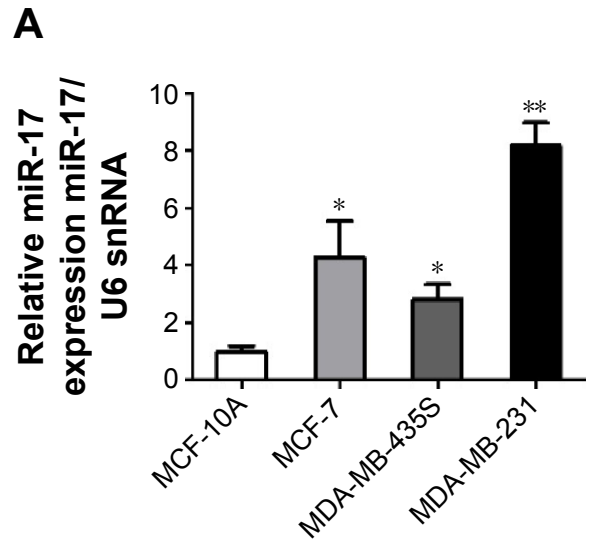

assays indicated that miR-17 mimics induced breast cancer cell proliferation (Figure 2B and C). In contrast, miR-17 inhibitor suppressed cell proliferation in breast cancer cells (Figure 2D and E). In addition to cell proliferation, we also investigated the role of miR-17 on cell cycle progression. Cell cycle profile was examined by flow cytometry with propidium iodide staining, and the cell numbers were counted according to the DNA content of $\mathrm{G} 0 / \mathrm{G} 1, \mathrm{~S}$, and $\mathrm{G} 2 / \mathrm{M}$ phases. The data showed that miR-17 inhibitor arrested cell cycle in $\mathrm{S}$ phases (Figure 2F). These data suggested that miR-17 increased cell proliferation and miR-17 inhibitor inhibited cell proliferation and arrested cell cycle in the S-phase.

\section{MiR-I7 induces tumor growth in vivo}

To measure the effect of miR-17 on tumor growth in vivo, we transfected MCF-7 cells with agomiR-17 (a modified miR-17 mimics used for in vivo studies). miR-17 was highly expressed in MCF-7 cells by qPCR (Figure 3A). The three batches of cells were injected subcutaneously into nude mice. After 42 days, we observed faster tumor growth in the agomiR-17 group compared with the control group (Figure 3B). The average weight of tumors from the two groups was significantly different (Figure 3C). These results showed that overexpression of miR-17 induced tumor growth in vivo.

\section{Overexpression of miR-I7 is associated with poor prognosis of breast cancer patients}

To further investigate the association of miR-17 expression with survival of breast cancer patients, Kaplan-Meier curve with long rank analysis was performed. Breast cancer patients with a low expression of miR-17 had a significantly longer survival time compared with those with a high expression of miR-17 ( $P=0.0044, P<0.05, \mathrm{n}=36$; Figure 4).

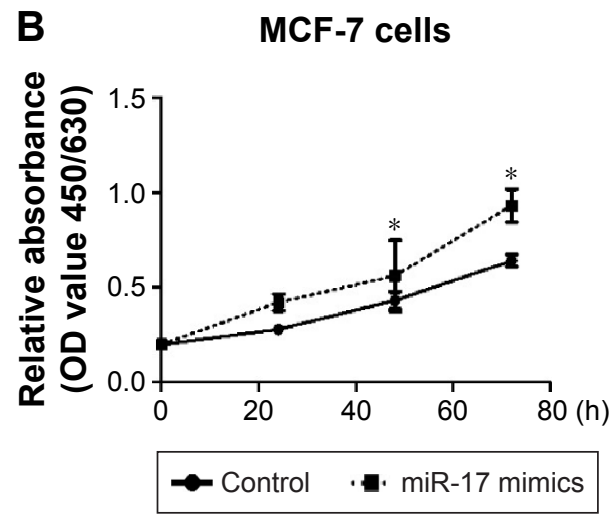



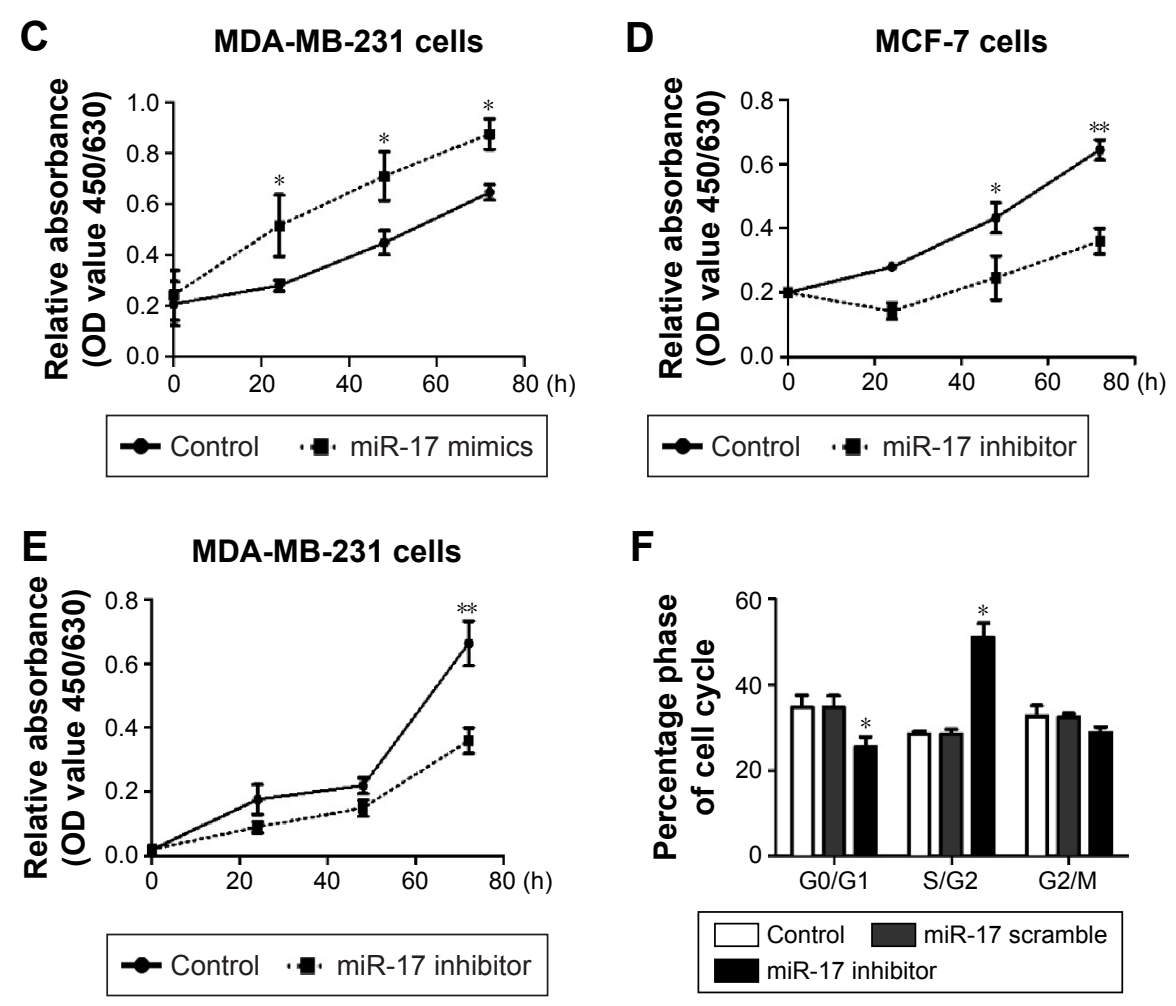

$\mathbf{F}$

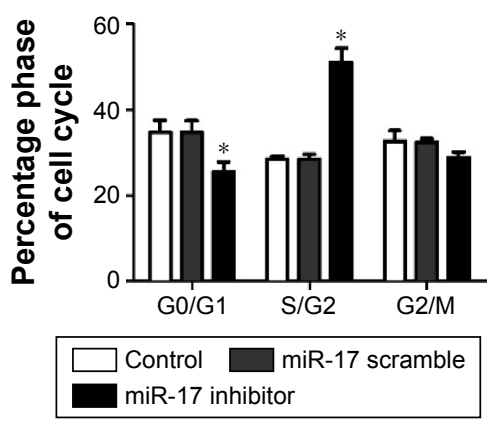

Figure 2 miR-17 regulated breast cancer cell proliferation and cell cycle arrest in vivo.

Notes: (A) miR-17 expression was examined by qRT-PCR and normalized to U6 snRNA expression in breast cancer cells compared with MCF-I0A (normal). (B and C) MTT detected miR-17 mimics effect on breast cancer cell proliferation. (D and E) MTT measured miR-17 inhibitor effect on breast cancer cell proliferation. (F) Cell cycle profile was examined by flow cytometry with propidium iodide staining, and the cell number was counted according to the DNA content of G0/GI, S/G2, and G2/M phases. The data were shown as mean \pm SD from three independent experiments with similar results. $* P<0.05$ and $* * P<0.01$.

Abbreviations: qRT-PCR, quantitative reverse transcription polymerase chain reaction; MTT, 3-(4,5-dimethylthiazol-2-yl)-2,5-diphenyltetrazolium bromide; OD, optical density; SD, standard deviation.

A

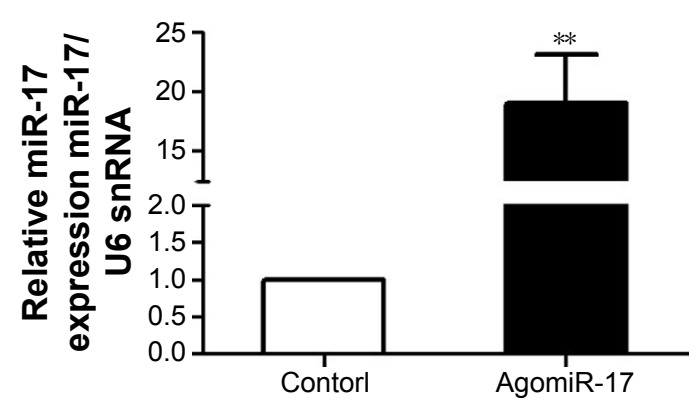

C

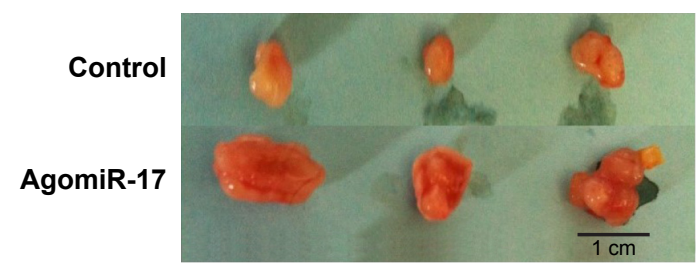

B
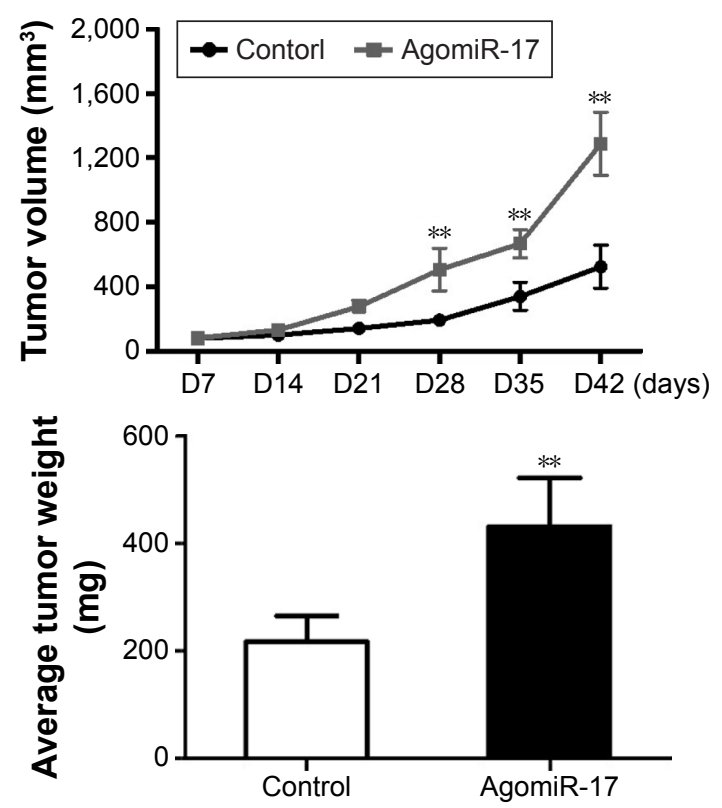

Figure 3 miR-I7 induced xenograft tumor growth in vivo.

Notes: (A) The expression of agomiR-17 was observed in MCF-7 cells by qPCR. (B) Nude mice were implanted subcutaneously with MCF-7 cells and MCF-7/agomiR-17 cells. Tumor volumes were recorded at the indicated times. (C) The tumor weight was measured when the mice were sacrificed. The data were shown as mean \pm SD from three independent experiments. $* * P<0.01$.

Abbreviations: qPCR, quantitative polymerase chain reaction; SD, standard deviation. 


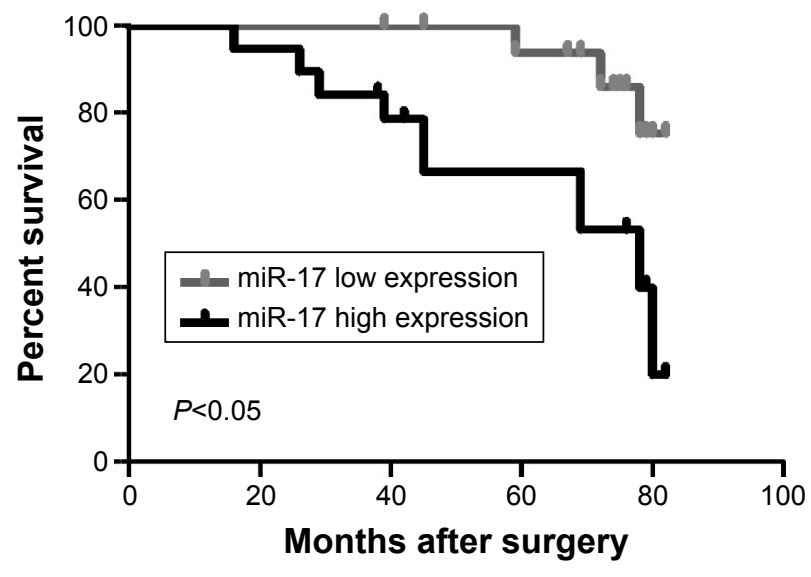

Figure 4 Relative miR-17 expression associated with overall survival of breast cancer patients.

Notes: Kaplan-Meier analysis of overall survival for patients with breast cancer according to miR-17 expression. Patients in the miR-17 high expression group had poorer prognosis than those in miR-I7 low expression group $(P<0.05)$.

These data suggested that miR-17 expression was a prognostic factor in breast cancer.

\section{Discussion}

There is mounting evidence demonstrating that miRNAs play an important role in the development of human malignancies, ${ }^{27-29}$ which exhibit oncogenic or tumor suppressive role by directly regulating oncogenes or tumorsuppressor genes. ${ }^{30,31}$

It would be conducive to expand our view to better understand cancer carcinogenesis by analyzing mRNA target association and miRNA-mediated pathways.

Here, we focused on miR-17, which had been shown to regulate growth, proliferation, apoptosis, migration, and invasion of tumor cells in certain cancers. The expression of miR-17 was significantly increased in prostate cancer, ${ }^{25,32}$ gastric cancer, ${ }^{33-35}$ and colon cancer cells, ${ }^{36-38}$ which suggests a potential tumor promoter function of miR-17. In this study, we observed that upregulation of miR-17 was a frequent event in breast cancer tissues compared with that in adjacent tissues. In addition, the expression level of miR-17 was higher in tumors with the pathological stage. We also found that miR-17 could induce cell proliferation in breast cancer cells and arrest cell cycle in the S-phase.

\section{Conclusion}

This study analyzed the association between miR-17 and the prognosis of breast cancer. We found that miR-17 was upregulated in breast cancer tissues and induced breast cancer cell proliferation. We provided evidence to verify that breast cancer patients with a low expression of miR-17 had a significantly longer survival time. These findings suggested that miR-17 might be a novel prognostic indicator and a potential target for diagnosis and gene therapy in breast cancer.

\section{Acknowledgment}

This work was supported by grants from the National Natural Science Foundation of China (81272240 to LF).

\section{Disclosure}

The authors report no conflicts of interest in this work.

\section{References}

1. DeSantis CE, Fedewa SA, Goding Sauer A, Kramer JL, Smith RA, Jemal A. Breast cancer statistics, 2015: convergence of incidence rates between black and white women. CA Cancer J Clin. 2016;66(1):31-42.

2. Manca G, Tardelli E, Rubello D, et al. Sentinel lymph node biopsy in breast cancer: a technical and clinical appraisal. Nucl Med Commun. 2016; 37(6):570-576.

3. Fan L, Goss PE, Strasser-Weippl K. Current status and future projections of breast cancer in Asia. Breast Care (Basel). 2015;10(6):372-378.

4. Russo A, Andreano A, Anghinoni E, et al. [A set of indicators to monitor the adherence to the guidelines for the diagnosis and treatment of breast cancer]. Epidemiol Prev. 2014;38(1):16-28. Italian [with English abstract].

5. Cardoso F, Harbeck N, Fallowfield L, Kyriakides S, Senkus E; Group EGW. Locally recurrent or metastatic breast cancer: ESMO Clinical Practice Guidelines for diagnosis, treatment and follow-up. Ann Oncol. 2012;23(suppl 7):vii11-vii19.

6. Wang D, Duan L, Tu Z, et al. The glasgow prognostic score predicts response to chemotherapy in patients with metastatic breast cancer. Chemotherapy. 2016;61(4):217-222.

7. Lu J, Getz G, Miska EA, et al. MicroRNA expression profiles classify human cancers. Nature. 2005;435(7043):834-838.

8. Lyons PJ, Poitras JJ, Courteau LA, Storey KB, Morin P Jr. Identification of differentially regulated microRNAs in cold-hardy insects. Cryo Letters. 2013;34(1):83-89.

9. Schneider MR, Samborski A, Bauersachs S, Zouboulis CC. Differentially regulated microRNAs during human sebaceous lipogenesis. J Dermatol Sci. 2013;70(2):88-93.

10. Winbanks CE, Ooi JY, Nguyen SS, McMullen JR, Bernardo BC. MicroRNAs differentially regulated in cardiac and skeletal muscle in health and disease: potential drug targets? Clin Exp Pharmacol Physiol. 2014;41(9):727-737.

11. Wang Y, Chen J, Lin Z, et al. Role of deregulated microRNAs in nonsmall cell lung cancer progression using fresh-frozen and formalinfixed, paraffin-embedded samples. Oncol Lett. 2016;11(1):801-808.

12. Vorvis C, Koutsioumpa M, Iliopoulos D. Developments in miRNA gene signaling pathways in pancreatic cancer. Future Oncol. 2016;12(9): 1135-1150.

13. Meryet-Figuiere M, Lambert B, Gauduchon P, et al. An overview of long non-coding RNAs in ovarian cancers. Oncotarget. 2016;7(28): 44719-44734

14. Lin CW, Lin PY, Yang PC. Noncoding RNAs in tumor epithelial-tomesenchymal transition. Stem Cells Int. 2016;2016:2732705.

15. Kwan JY,Psarianos P, Bruce JP, YipKW,LiuFF. The complexity ofmicroRNAs in human cancer. J Radiat Res. 2016;57(suppl 1):i106-i111.

16. Fred Henry Walter R, Vollbrecht C, Werner R, et al. microRNAs are differentially regulated between MDM2-positive and negative malignant pleural mesothelioma. Oncotarget. 2016;7(14):18713-18721.

17. Feng T, Xu D, Tu C, et al. MiR-124 inhibits cell proliferation in breast cancer through downregulation of CDK4. Tumour Biol. 2015;36(8): 5987-5997. 
18. Treece AL, Duncan DL, Tang W, et al. Gastric adenocarcinoma microRNA profiles in fixed tissue and in plasma reveal cancer-associated and Epstein-Barr virus-related expression patterns. Lab Invest. 2016; 96(6):661-671.

19. Gomes BC, Santos B, Rueff J, Rodrigues AS. Methods for studying MicroRNA expression and their targets in formalin-fixed, paraffinembedded (FFPE) breast cancer tissues. Methods Mol Biol. 2016; 1395:189-205.

20. Han Y, Xu GX, Lu H, et al. Dysregulation of miRNA-21 and their potential as biomarkers for the diagnosis of cervical cancer. Int J Clin Exp Pathol. 2015;8(6):7131-7139.

21. Wen J, Ye F, He X, et al. Development and validation of a prognostic nomogram based on the log odds of positive lymph nodes (LODDS) for breast cancer. Oncotarget. 2016;7(15):21046-21053.

22. Fang Y, Xu C, Fu Y. MicroRNA-17-5p induces drug resistance and invasion of ovarian carcinoma cells by targeting PTEN signaling. J Biol Res (Thessalon). 2015;22:12.

23. Cohen R, Greenberg E, Nemlich Y, Schachter J, Markel G. miR-17 regulates melanoma cell motility by inhibiting the translation of ETV1. Oncotarget. 2015;6(22):19006-19016.

24. Jin YY, Andrade J, Wickstrom E. Non-specific blocking of miR-17-5p guide strand in triple negative breast cancer cells by amplifying passenger strand activity. PLoS One. 2015;10(12):e0142574.

25. Zhou P, Ma L, Zhou J, et al. miR-17-92 plays an oncogenic role and conveys chemo-resistance to cisplatin in human prostate cancer cells. Int J Oncol. 2016;48(4):1737-1748.

26. Conev NV, Donev IS, Konsoulova-Kirova AA, Chervenkov TG, Kashlov JK, Ivanov KD. Serum expression levels of miR-17, miR-21, and miR-92 as potential biomarkers for recurrence after adjuvant chemotherapy in colon cancer patients. Biosci Trends. 2015;9(6):393-401.

27. Palanichamy JK, Rao DS. miRNA dysregulation in cancer: towards a mechanistic understanding. Front Genet. 2014;5:54.

28. Mulrane L, McGee SF, Gallagher WM, O'Connor DP. miRNA dysregulation in breast cancer. Cancer Res. 2013;73(22):6554-6562.
29. Iliopoulos D, Polytarchou C, Hatziapostolou M, et al. MicroRNAs differentially regulated by Akt isoforms control EMT and stem cell renewal in cancer cells. Sci Signal. 2009;2(92):ra62.

30. Eroles P, Tormo E, Pineda B, Espin E, Lluch A. MicroRNAs in breast cancer: one more turn in regulation. Curr Drug Targets. 2016;17(9): 1083-1100.

31. Liu H. MicroRNAs in breast cancer initiation and progression. Cell Mol Life Sci. 2012;69(21):3587-3599.

32. Gong AY, Eischeid AN, Xiao J, et al. miR-17-5p targets the p300/ $\mathrm{CBP}$-associated factor and modulates androgen receptor transcriptional activity in cultured prostate cancer cells. BMC Cancer. 2012;12:492.

33. Bahari F, Emadi-Baygi M, Nikpour P. miR-17-92 host gene, uderexpressed in gastric cancer and its expression was negatively correlated with the metastasis. Indian J Cancer. 2015;52(1):22-25.

34. Zhang X, Kong Y, Xu X, et al. F-box protein FBXO31 is down-regulated in gastric cancer and negatively regulated by miR-17 and miR-20a. Oncotarget. 2014;5(15):6178-6190.

35. Wu Q, Luo G, Yang Z, et al. miR-17-5p promotes proliferation by targeting SOCS6 in gastric cancer cells. FEBS Lett. 2014;588(12): 2055-2062.

36. Zhu J, Dong H, Zhang Q, Zhang S. Combined assays for serum carcinoembryonic antigen and microRNA-17-3p offer improved diagnostic potential for stage I/II colon cancer. Mol Clin Oncol. 2015;3(6): 1315-1318.

37. Knudsen KN, Nielsen BS, Lindebjerg J, Hansen TF, Holst R, Sorensen FB. microRNA-17 is the most up-regulated member of the miR-17-92 cluster during early colon cancer evolution. PLoS One. 2015; 10(10): 0140503

38. Hu S, Liu L, Chang EB, Wang JY, Raufman JP. Butyrate inhibits pro-proliferative miR-92a by diminishing c-Myc-induced miR-17-92a cluster transcription in human colon cancer cells. Mol Cancer. 2015; 14(1): 180 


\section{Supplementary material}

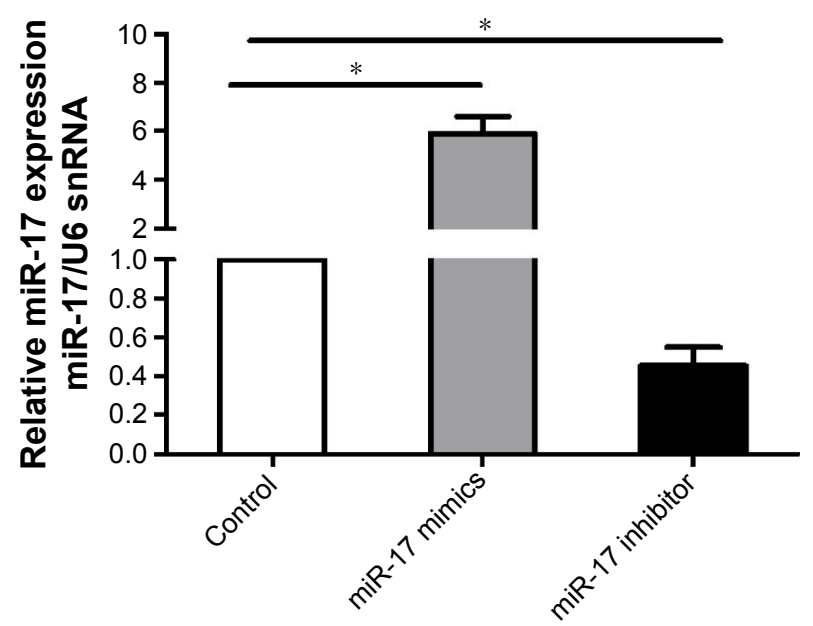

Figure SI The expression of miR- 17 in breast cancer cells.

Notes: MCF-7 cells with miR-17 mimics and miR-17 inhibitor treatment, and miR-17 expression was examined by qRT-PCR and normalized to U6 snRNA expression in breast cancer cells. The data were shown as mean \pm SD from three independent experiments. $* P<0.05$.

Abbreviation: qRT-PCR, quantitative reverse transcription polymerase chain reaction.

\section{Publish your work in this journal}

OncoTargets and Therapy is an international, peer-reviewed, open access journal focusing on the pathological basis of all cancers, potential targets for therapy and treatment protocols employed to improve the management of cancer patients. The journal also focuses on the impact of management programs and new therapeutic agents and protocols on

patient perspectives such as quality of life, adherence and satisfaction. The manuscript management system is completely online and includes a very quick and fair peer-review system, which is all easy to use. Visit http://www.dovepress.com/testimonials.php to read real quotes from published authors. 